\title{
Predicting Sea-Level Rise in Al Hamra Development, Ras Al Khaimah, UAE
}

\author{
Robert M. Arthur ${ }^{*, a}$, and G. G. Garland ${ }^{\mathrm{b}}$ \\ ${ }^{a}$ American University of Ras Al Khaimah UAE, \\ ${ }^{b}$ Independent Coastal Management Consultant, UAE
}

\begin{abstract}
The Al Hamra development in the emirate of Ras Al Khaimah is situated along the south-eastern coast of the Arabian Gulf. The development fronts the Gulf along a $5 \mathrm{~km}$. stretch of sandy beach and, as it includes 5 hotels, numerous villas and condos, represents a significant investment. Such an investment requires long-term strategies to minimize risk from sea level rise. As IPCC reports continue to be updated with new information, predictions of sea level rise have been revised upward. In order to plan for the protection of these, and other developments, accurate information needs to be supplied to those involved in planning adaptation strategies. This paper seeks to quantify and map the potential area subject to inundation up to the year 2099. Using the highest inundation scenario, a GIS map of inundation will be created. Other factors, such as high tides, storm surge and extreme wave events will see water levels increased beyond the predicted sea level scenarios indicating greater risk of flooding. This project will use LiDAR data in a GIS environment to provide the most accurate elevation data. Other layers showing buildings assist in visualizing future vulnerability to sea level rise. This coastline is heavily developed with construction underway for more resort developments. As the risk from sea level rise evolves over a long time period, planners require accurate information that can be easily updated in order to react to revised predictions. This paper represents a pilot project as future research is planned to examine the entire $65 \mathrm{~km}$ coastline of Ras Al Khaimah.
\end{abstract}

Keywords: Sea Level Rise, GIS, LiDAR, Ras Al Khaimah

\section{Introduction}

Climate change is bringing about many challenges for the human populace to adapt to, not the least of which is the rise in level of the Earth's oceans. A great deal of the world's population lives within close proximity to oceans (Cohen et al. 1997) and, with an acceleration of development along coastlines, over 500 million people could be directly affected by 2100 (Poulter and Halpin 2008; Nicholls 2004, Nicholls 2002). Anthropogenic activities increase the risk to coastlines, not the least being the destruction of mangroves and marshes that serve to protect coastlines from erosion and storm surge (Collin and Melloul, 2014). Encroachment of sea water can lead to flooding and the subsequent damage to buildings and infrastructure, it can damage coastal ecosystems such as marshlands and mangrove forests, and it will damage underground water resources by increasing salination in the aquifer (Collin and Melloul, 2014).

${ }^{*}$ Corresponding author

E-mail: robert.arthur@aurak.ac.ae

(C) 2015 International Association for Sharing Knowledge and Sustainability

DOI: $10.5383 /$ swes.7.02.004
As temperatures continue to rise, glaciers and polar caps melt, adding more volume to the oceans. Concurrently, oceans increase in temperature causing thermal expansion. The net result is a continued, measured rise in mean sea levels worldwide (IPCC 2013) causing a slow inundation of shorelines (Sanders 2007). The increase in mean sea level is predicted to have several important effects: higher extreme tides, more frequent and more powerful storms. These will cause stronger storm surges resulting in higher waves, all of which will further erode the coastline (Demirkesen et al. 2008; Muthusankar et al. 2013). Adding to this concern is the prediction that these events increase in frequency. Kellet et al. (2014) predicts that once in a hundred years events will become as commonplace as to occur two to three times a year by 2099 . The concern over damage to infrastructure, buildings, 
coastlines as well as the threat to human life from these flood events has engendered much research.

This paper will discuss several strategies to mitigate such events: planning policies, physical structure improvement, and emergency preparedness (Sanders 2007). The United Arab Emirates, located at the South-Eastern end of the Arabian Gulf, has invested greatly in development along its coastline. Many of these developments will be at risk from future sea level rise (Garland 2010). Going through a phase of rapid economic growth, the UAE is experiencing urban growth at an unprecedented pace. A great deal of this development is along the coastline, in fact many developments are being constructed on land reclaimed from the sea, such as the famous Palms projects in Dubai. It is wise to begin consideration of development and planning policies now to protect these investments in the future. In a newspaper article (Hamdan 2007) mentions concerns that the governments of the Arab States have been slow to react to the concepts of climate change and the dangers of sea level rise.

This paper examines the risk to the coastline of the emirate of Ras Al Khaimah, the northernmost emirate in the UAE. It has a shoreline of approximately $65 \mathrm{kms}$. with many low lying offshore islands and sandy beaches. Risk of inundation will be modelled in a GIS environment using several criteria. These criteria will include low and high sea level rise predictions for 2099 based upon the 2013 paper released by the IPCC. Future tidal changes and extreme wave heights as determined by recorded government data will also be factored in. Predictions of changes in weather patterns resulting from global warming include storms of higher intensities and that they would occur more frequently (IPCC 2013). However, due to the complexity of climatic models, it is not possible at this time to predict these storms with any specificity. It is obvious though, that these storms will create higher storm surges and extreme wave events, increasing the risk of flooding along coastlines. The worst case scenarios predicted in this paper are determined by using recorded local extreme wave heights resulting from storm systems as well as tidal changes. By combining these with the predicted sea level rise a worst case is generated. Complex techniques are required to determine the vulnerability along coastlines (Goble and Mackay 2013). As this has not been evaluated at this time, exposure to risk has been placed in two categories: exposure to the open sea, and sheltered sites. Sheltered sites are those that are protected from direct exposure to waves by off shore islands or are inlets and lagoons. The methodology employed to determine inundation will be to model elevation of the study are within a GIS environment. Light Ranging and Detecting (LiDAR) data has been acquired from the area which will provide accurate elevation measurements. Once the relief of the area is determined, all pixels with an elevation value less than that predicted in the two scenarios and contiguous to the coast will be considered to be inundated. The simple $\mathrm{k}=8$ rule will be utilized as explained later.

\section{The Study Area}

The name 'Ras Al Khaimah' can be translated as meaning 'the top of the tent'. This illustrates the fact that Ras Al Khaimah is the northernmost emirate in the UAE. The territory of Ras Al Khaimah is divided into two separate areas by the emirate of Fujairah. The study area considered in this paper consists of the northen region which is bordered by the Musandam peninsula of Oman to the north, Fujairah to the east, Umm Al Qawain and Fujairah to the south, and the Arabian Gulf to the west (figure 1). The capital city of Ras Al Khaimah, also called Ras Al Khaimah, lies within the northern region. It, and its' suburban developments occupy the entire coastline.

The city of Ras Al Khaimah is situated on an alluvial plane formed by sediments deposited from the Hajar Mountains which form the eastern border of the emirate. This plain narrows to the north towards Oman's Musandam peninsula. The coastline is mostly sandy, marked by several lagoons, sand spits and numerous low lying off-shore islands. Towards the southern extent of the city of Ras Al Khaimah the coastline is backed by a plain of red sand which is the northernmost extension of the Rub Al Khali, or the Empty Quarter. The coastline has been extensively developed and harbour dredging from the four ports of Ras Al Khaimah has disturbed the natural flow of sediments along this coastline (Gouldie et al. 2000). In the last ten years, the city of Ras Al Khaimah has undergone extensive growth that continues with more developments in the planning stages. The coastline especially has seen rapid growth in resort developments as the city capitalizes on its warm sunny weather and sandy beaches. At the southernmost location of the coastline is the new Marjan Island complex which is built on four manmade islands connected to each other. It covers almost 3 million square meters and extends four and a half kilometres into the Gulf. Still under construction, Marjan Island will include residences, a number of hotels, a town centre, a theme park, floating villas, a marina and a resort branded with the Real Madrid sports club name (alhamravillage.com/discover-en/al-marjan-island.html). To the north of Marjan Island is Al Hamra Village, the study area of this paper. Mina Al Arab, another large development is the next northerly new development that is partially complete; it too has villas and apartments (completed) with several hotels to be built on three nearshore manmade islands. Several resorts have been built along the coast, most notably the Cove Rotana and the Hilton Spa and Resort, two large complexes. There are other projects along the coast that are in the planning phase, some which will include off shore islands or the creation of manmade made islands. 


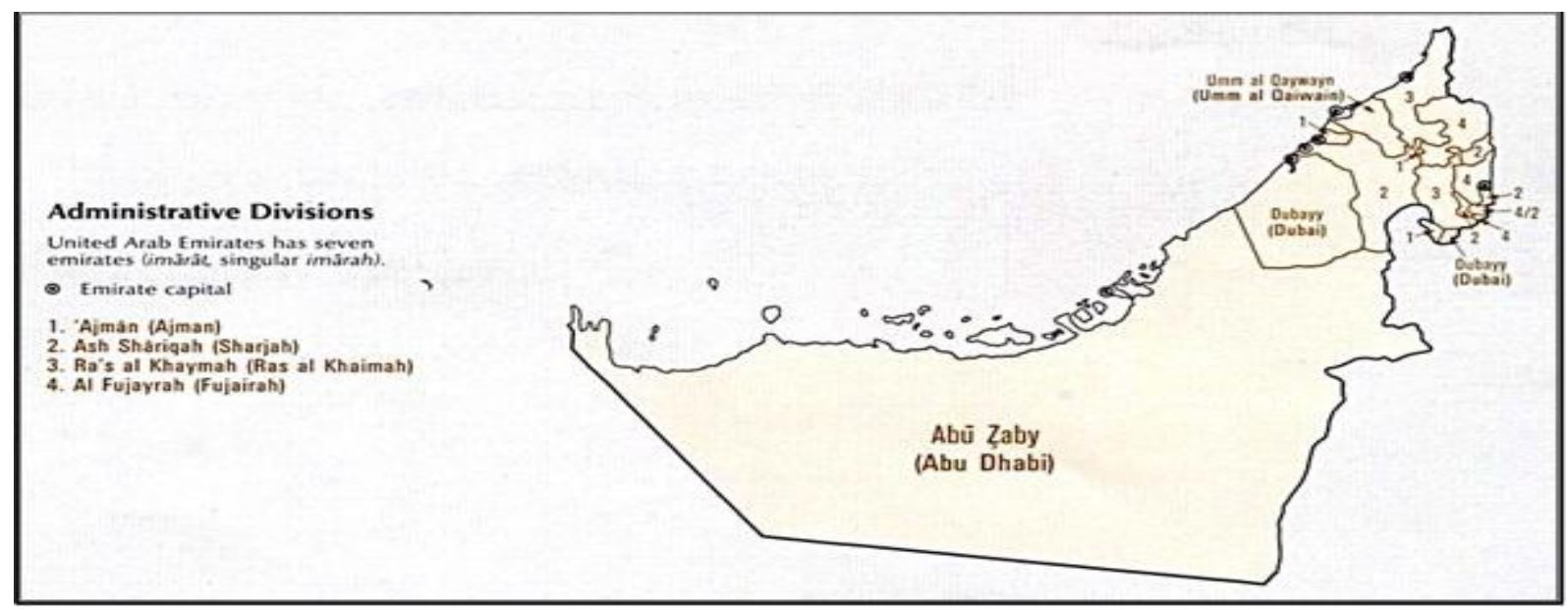

Figure 1: The United Arab Emirates (Administrative Districts)

Source: Courtesy of the University of Texas Libraries, the University of Texas at Austin. [CIA Maps, 1993]

There are many other features at risk along the coast other than resort developments. There are four ports and the old downtown area which has many homes close to the coast. Just north of Al Hamra is the village of Jazirat where one of the ports is located, along with many residences that will be at risk, and a historical site of an old abandoned village; all on low lying ground and subject to inundation. Most notably in danger are the mangrove stands. These are important, diverse, ecosystems that perform many useful functions. They serve as breeding grounds for all forms of marine life and they protect the coastline from erosion being particularly effective at dispersing the energy from extreme wave events. Mangroves require a particular depth of water, when the water becomes too deep, the mangroves migrate by dying off in the deep water and colonizing further inland as the water rises there. Unfortunately, the mangroves are bordered on the landward side by built developments, effectively cutting off their migration. This does not bode well for the mangroves in the long run. The importance of protecting these sites is of importance to the economy, heritage, and well-being of the residents of Ras Al Khaimah. Ras Al Khaimah has an extremely arid climate, receiving only $120 \mathrm{~mm}$ annually. The highest tides occur in the spring reaching between 1.7 and 1.9 meters above mean sea level. There are also two wind drift potential peaks, one from the SE at $31.1 \%$ of the total, and the other at $35.51 \%$. The highest waves are experienced in the winter months, particularly in December and March, reaching greater than $2.44 \mathrm{~m} 1 \%$ of time; this is due to the north westerly Shamal winds occurring at that time. No data is available measuring sediment transport, but it does appear as if the general direction is northward. Ras Al Khaimah sits on a narrow plain composed of sand dunes, sabkah and alluvial fans. At the northernmost location, the plains narrow as the mountains slope directly into the Gulf (Gouldie et al. 2000).

\section{Geomorphological Change of the RAK Shoreline}

Gouldie et al. (2000) assessed the change in geomorphology of the Ras Al Khaimah coastline from 1819 to 2000. They used historical maps and documents as well as recent air photos. They determined that the coastline has three individual zones: a $14 \mathrm{~km}$ long southern section, with two sabkahs; an $11 \mathrm{~km}$ long central zone on a long narrow lagoon which includes Ras Al Kaimah city; and, finally, a 9 km long northern section which incorporates a creek and an area of mangroves. They pointed out that Jazirat Al Hamra, in the south, has been significantly subjected to dredging and harbour construction and is currently retreating towards the southern end, although, the northern end appears to have been stable for a number of decades according to historical maps.

From 1822 to 1958 the spit located in the central area has been moving northwards at a rate of approximately $40 \mathrm{~m}$ per year. Later on it was breached towards its southern end. After that, the southern portion moved northwards at approximately $140 \mathrm{~m}$ per year and created a detached continuous sand bar. Also, substantial land reclamation has occurred in the area. To the north is the region of Jazirat Hulaylah which benefits from a natural stability protecting the shoreline from change due to natural causes. The Ras Al Khaimah Free Trade Zone has constructed a large industrial complex in this area which has significantly impacted the area (Gouldie et al 2000).

With respect to the present study, much of the Ras Al Kaimah shoreline must be considered as geomorphologically mobile and, therefore, as likely to change. This being the case, it is probable that higher future sea levels will exacerbate natural rates of change, a consideration which should be included in the assessment of future risk to the region. 


\section{Expected Sea Level Rise along the Ras Al Kaimah Coast Line}

Garland (2010) examined all relevant information regarding sea level change in the Abu Dhabi region. This review included possible storm and tide surges, determining the probable highest significant waves.

This review included global information from Pfeffer et al (2008), IPCC (2007), Rhamsdorf et al (2007) as well as studies pertaining to the Arabian Gulf, Manger et al. (2008), Hossienibalam et al. (2007), Neelamani et al. (2007), Sultan et al. (1995) and El Sabh and Murty (2008). Garland's analysis concluded that the change in sea level within the Arabian Gulf parallels that of the eustatic change globally. As much of the data was gathered for the city of Dubai and Ras Al Khaimah is just over $100 \mathrm{~km}$ north east of Dubai and about $240 \mathrm{~km}$ north of Abu Dhabi, it is reasonable to assume that the change in sea level in Ras Al Khaimah will be similar to the findings in Garland's study.

Further evidence of wind driven, low pressure storm surge waves occurred just recently (Feb. 21, 2015) when a storm brought 10 foot high waves to Sharjah, just 90 kilometres south of Ras Al Khaimah, forcing the closure of the Corniche (the main road parallel to the coast) due to flooding (www.emerates24/7.com).

Table 1: Predicted Sea Level Rise Scenarios for the Southern Arabian Gulf

\begin{tabular}{|l|l|l|l|l|}
\hline & $\begin{array}{l}\text { Low } \\
\text { scenario } \\
\text { (Sultan } \\
\text { et al, } \\
\text { 1995) }\end{array}$ & $\begin{array}{l}\text { Medium } \\
\text { scenario } \\
\text { (IPCC, }\end{array}$ & $\begin{array}{l}\text { High } \\
\text { secenario } \\
\text { (Rhamsdorf } \\
\text { et al, 2007) }\end{array}$ & $\begin{array}{l}\text { Extreme } \\
\text { scenario } \\
\text { (Pfeffer } \\
\text { et al } \\
\text { 2008) }\end{array}$ \\
\hline $\begin{array}{l}\text { Annual } \\
\text { sea } \\
\text { level } \\
\text { change } \\
\text { in mm }\end{array}$ & $\mathbf{+ 2 . 1 m m}$ & $\mathbf{+ 6 . 6 m m}$ & $\mathbf{+ 9 . 0 m m ~}$ & $\mathbf{+ 2 0 . 2 m m}$ \\
\hline $\begin{array}{l}\text { Sea } \\
\text { level } \\
\text { change } \\
\text { by } \\
\text { 2099 in } \\
\text { m }\end{array}$ & $\mathbf{+ 0 . 2 1 m}$ & $\mathbf{+ 0 . 5 9 m}$ & $\mathbf{+ 0 . 8 1 m}$ & $\mathbf{+ 2 . 0 m}$ \\
\hline
\end{tabular}

Table 1 summarizes several sea level rise scenarios as predicted to the year 2099. Table 2 contains eight possible inundation levels as predicted for the year 2099 by combining estimated sea level rise with the sporadic effects of storm surges, tidal surges and extreme wave events. This information is then categorized into two distinct groups; areas exposed to the open sea and areas protected from direct exposure such as lagoons or harbours (sheltered sites). Sheltered sites have had the extreme wave heights removed from their calculations. These two groups are subdivided into 4 cases, each reflecting the various sea level scenarios as predicted by experts.
Table 2: Expected maximum inundation levels above present datum, comprised of sea level change, extreme tides, storm surges and high wave events, for Ras Al Kaimah by 2099

\begin{tabular}{|l|l|l|}
\hline $\begin{array}{l}\text { Expert total Sea } \\
\text { level rise by 2099 }\end{array}$ & $\begin{array}{l}\text { Sheltered sites } \\
\text { (including storm } \\
\text { and tide surges, } \\
\text { but excluding } \\
\text { wave and effects) }\end{array}$ & $\begin{array}{l}\text { Sites exposed to } \\
\text { open sea } \\
\text { (including storm } \\
\text { and tide surges, } \\
\text { and expected } \\
\text { highest } \\
\text { significant } \\
\text { waves) }\end{array}$ \\
\hline $\begin{array}{l}\mathbf{+ 0 . 2 1 m} \text { (Sultan et } \\
\text { al 1995) }\end{array}$ & $+4.1 \mathrm{~m}$ & $+8.21 \mathrm{~m}$ \\
\hline $\begin{array}{l}\mathbf{+ 0 . 5 9 m} \text { (IPCC } \\
\text { 2007) }\end{array}$ & $+4.59 \mathrm{~m}$ & $+8.59 \mathrm{~m}$ \\
\hline $\begin{array}{l}\mathbf{0 . 8 1 m} \text { (Rhamsdorf } \\
\text { et al 2007) }\end{array}$ & $+4.81 \mathrm{~m}$ & $+8.81 \mathrm{~m}$ \\
\hline $\begin{array}{l}\mathbf{+ 2 . 0 m} \text { Pfeffer et al } \\
\text { 2008) }\end{array}$ & $+6.0 \mathrm{~m}$ & \\
\hline
\end{tabular}

Source: Garland, 2010.

\section{The Study Area}

The development of Al Hamra was chosen for the study site for several reasons, it has a continuous sandy beach coast, contains two distinct areas of sheltered and exposed sites, and has been extensively developed. Al Hamra development surrounds a lagoon and a golf course, it includes several highand low-rise apartments (approximately 2,500), villas and townhouses $(1,000)$, a marina, five hotel resorts including the 5 star Waldorf Astoria, a shopping mall and a smaller strip mall (alhamravillage.com). The development is approximately 4.3 square kilometres in area including the lagoon. If the lagoon is excluded, the land area is approximately 3.35 square kilometres (figure 2).

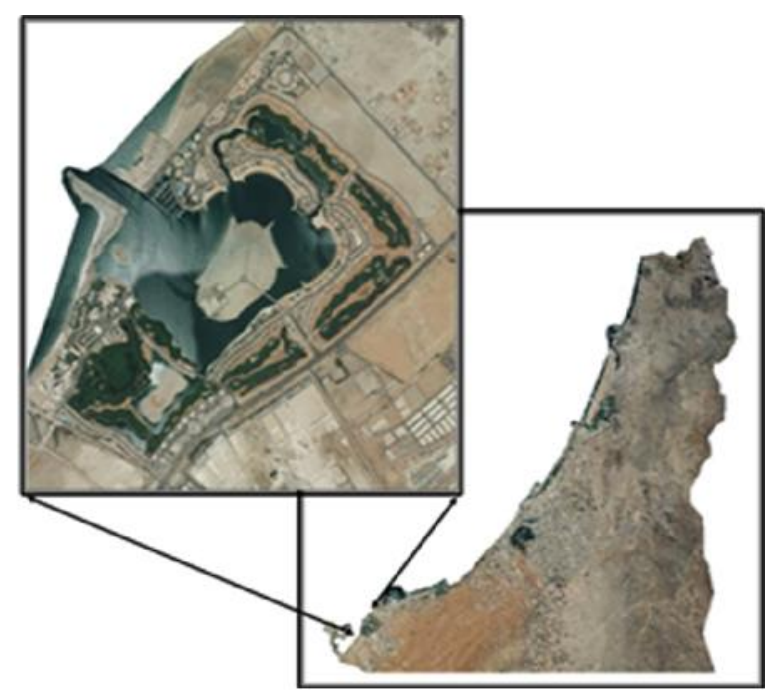

Figure 2: The Ras Al Khaimah and Al Hamra Village Coastline 


\section{GIS Modeling}

GIS layers and LiDAR data were generously supplied by the municipality of Ras Al Khaimah. The LiDAR data is extremely important as it provides the most accurate elevation data. In areas of low relief, accuracy of elevation measurements are crucial as horizontal values determined during analysis can be seriously distorted. This because a small change in height can result in a large change in horizontal distance (Fraile-Jurado and Ojeda-Zújar 2012). Figure 3 illustrates this principle.

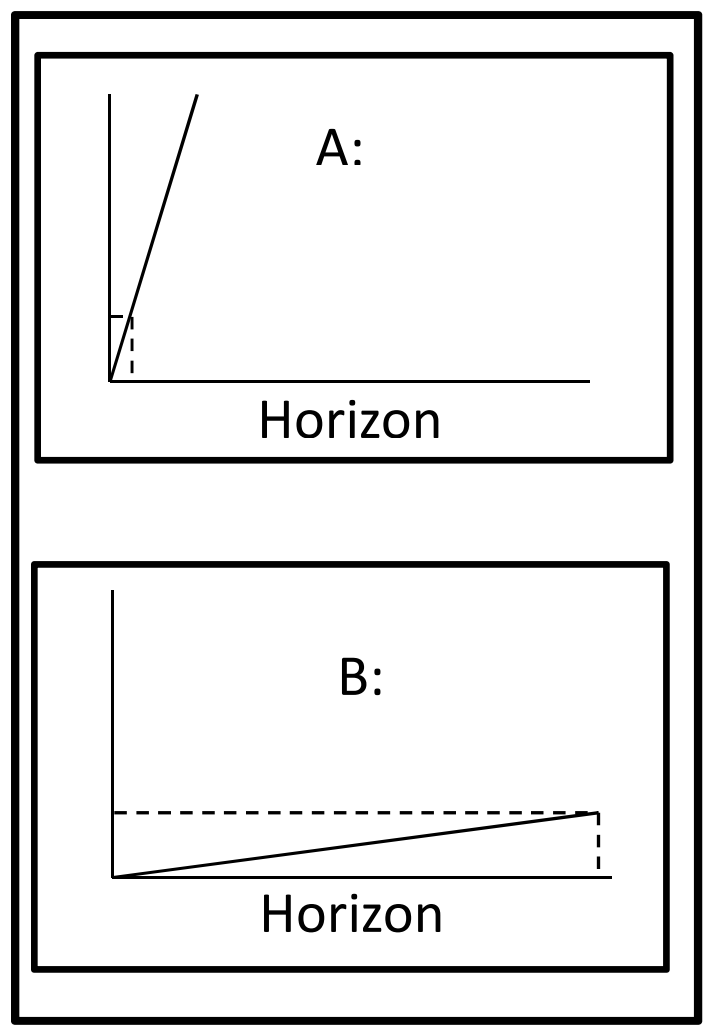

Figure 3: Change in Horizontal Distance Resulting From a Change in Vertical Distance

The GIS layers for the study were extracted from the original dataset that covered the entire emirate of Ras Al Khaimah. Using 'heads-up' digitizing with the aid of an orthophoto also supplied by the municipality, road and coastline layers were created. The first model produced determined inundation to the $2 \mathrm{~m}$ sea level rise scenario. All pixels in the elevation model with values between 0 and 2 were extracted; any pixels not contiguous to open water were erased. This technique is known as the 'bathtub' or 'bucket' approach and is the method most commonly used to assess coastal inundation using GIS (Kellet et al. 2014, Poulter and Halpin 2008). These pixels represented the area of inundation. Connectivity between pixels can be determined in two different ways, the 4 point rule or the 8 point rule (Poulter and Halpin 2008).
The 4 point rule connects pixels only in the cardinal directions and has a tendency to under estimate whereas the 8 point rule connects by cardinal direction and diagonally across the corners.

The 8 point rule tends to overestimate, the 8 point rule was chosen as the cautionary principle would suggest (see Figure 4).

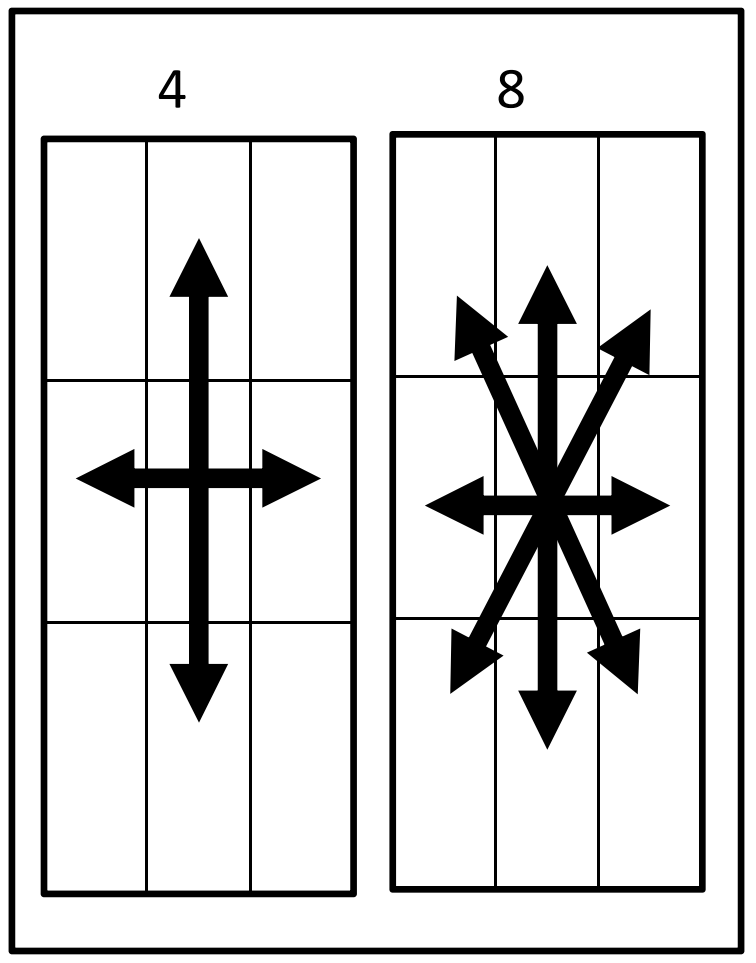

Figure 4: The 4 Point and 8 Point Rule Illustrated

Forecasts continue to change as more data is recorded and used presenting the modeller with the need to be able to incorporate these changes and update the model. The flexibility and ease by which different scenarios can be modelled makes GIS an exceptional tool for prediction of coastal inundation due to sea level rise. With longer term data collection, trends can be identified with greater precision. This flexibility afforded by GIS is necessary considering varying conditions of global warming, climate change, and the resulting sea level rise.

First, the lowest and highest sea level rise scenarios as per table 1 were modelled. Figure 5 illustrates the results of the $2 \mathrm{~m}$ worst case scenario. The red pixels represent areas that will be inundated in such a situation. The total area inundated is 777,200 square meters. Figure 5 shows how a $2 \mathrm{~m}$ rise will result in significant encroachment of the Gulf into the coastal zone with waters spreading substantially along Al Hamra's northern border. The southern edge is also threatened by inundation as it is a low lying region; however it is not illustrated in figure 5 as it lies outside the study area. The remaining area of the development not inundated lies only up 
to $4 \mathrm{~m}$ above the new mean sea level. Taking into account the lowest scenario in table 2 (sea level rise and other effects) is 4.1 meters, the consequences for the Al Hamra development could be disastrous. Water would cover the entire development including where the mall is located and would continue over the highway marking the western border of the development. With this in mind, it was deemed not necessary to model all eight scenarios. Given this worrying state of affairs, it would seem prudent for Ras Al Khaimah's government to explore remedial action.

\section{Remediation}

For the most part, governments worldwide approach the issue of sea level rise as a global warming issue and take action through the reduction of carbon emissions (Stokke 2014, Tayler et al. 2013). In reviewing studies from Norway and Australia it was found that governments show little preparation to protect areas from the risk of sea level rise. Predictions of sea level rise and environmental damage contain elements of doubt and change in sea level is very gradual over a long period of time. As a result, planning agencies have a tendency to not commit to protective policies. To change the value of developed land, or downgrade its value is likely to have negative repercussions from the community (Kellet et al. 2014). Planning agencies have three distinct methods to resort to when determining how to protect endangered coastlines: protect, accommodate, or retreat (Kellet et al. 2014). Protection can take

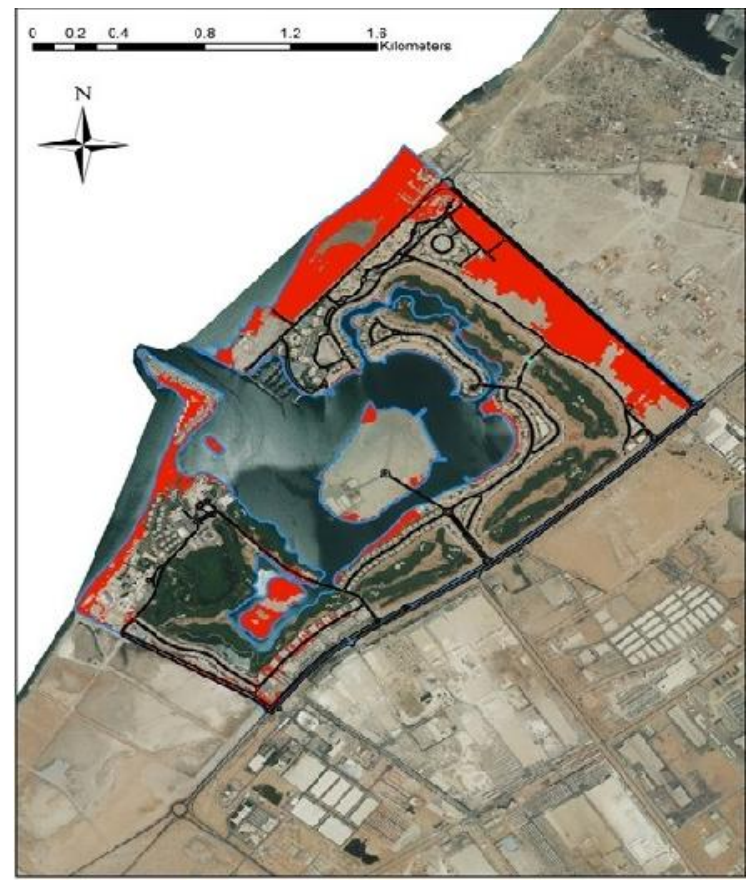

Figure 5: Inundation Map of Al Hamra Development

two forms: hard protection, which requires the construction of sea walls, levees or dikes, and soft protection which takes advantage of natural features such as Mangrove stands, sand dunes, wetlands and tidal flats. Physically altering infrastructure and buildings to protect them from encroaching flood waters is the strategy of accommodation. This, like protection requires extensive outlays of capital and must be assessed thoroughly before acting. While being the cheaper solution, retreat, or abandonment, still incurs the cost of losing, or moving, viable buildings and infrastructure. The use of set-back lines would allow planners to zone areas at risk and prevent future construction in demarcated zones, or, if a developer wishes to build in these zones, it must be shown what modifications will be put in place to protect the development form future inundation.

The planners will then have the opportunity to accept or reject the plans. Set back lines can also be used in market oriented strategies. Development within such zones would see their insurance costs rise significantly as well as a dramatic drop in the land value for properties in the risk zones, and an increase in values for those properties in areas deemed safe. This lassez-fare, market oriented policy was suggested by Lee (2014). Sahin et al. (2013) also mentioned the 'do nothing" strategy which is to just accept the risk and avoid costs of adapting. Furthermore, in conjunction with the "do nothing" approach, is to improve public awareness of risk. While this method does not directly protect areas at risk, there will be market reactions such as described above. Increased public awareness can result in the creation of grass roots movements that can become politically active and pressure governments to address the issue.

\section{Conclusion}

Every time IPCC issues its reports, predictions of sea level rise are revised upwards. This is due to better information and longer term longitudinal information that improve the determination of trends and forecasting. Kellet et al. (2014) warns us that current research shows that sea levels are "tracking at, or near, the upper limit of the IPCC worst case projections". As this paper shows, GIS aided with remote sensing technologies has proven itself as a flexible and useful tool for assessing coastline areas that will be at risk from sea level rise. Furthermore, GIS's flexibility allows for other information such as high tides, storm surges and extreme wave events to be evaluated and combined with the changing predictions of sea level rise. Government agencies, planners, developers, and home owners will need to prepare for the future consequences of sea level rise and inundation. Strategies need to be decided upon to effectively protect areas at risk, including the setting aside of monies and resources. Regardless of the strategy or strategies chosen, GIS has the capability to predict, analyse and assess risk of endangered coastal areas.

Using GIS and LiDAR data, this paper has assessed the future risk of inundation posed to the large multi-use coastal development of Al Hamra. Future research will examine the entire $65 \mathrm{~km}$. coastline of Ras Al Khaimah and eventually will include dynamic modelling of wave and tide action. These models can then be used in three ways: first, to assess the value of the existing buildings and infrastructure that are at risk; second, to develop new planning policies, such as set back lines, through which future developments are restricted; and, third, determining flood zones and as a tool for 
emergency preparedness should future extreme wave events occur.

\section{Acknowledgement}

This paper has been funded through an internal grant provided by the American University of Ras Al Khaimah. The authors' also wish to thank the Municipality of Ras Al Khaimah for providing GIS data, including LiDAR data. We would like to thank Dr. Richard Gauvain for his thoughtful comments.

\section{References}

[1] alhamravillage.com, accessed August 8, 2014.

alhamravillage.com/discover-en/al-marjan-island.html, accessed August 9, 2014.

[2] Cohen, J. E., Small, C., Mellinger, A., Gallup, J., \& Sachs, J. 1997. 'Estimates of coastal populations'. Science, 278, pp.1211-1212.

[3] Demirkesen, Ali C., Evrendilek, Faith, Berberoglu. Suha. 2008. 'Quantifying Coastal Inundation Vulnerablity of Turkey to Sea-Level Rise'. Environmental Monitoring and Assessment. 138, pp.101-106.

[4] El Sabh, M., I., \& Murty, T., S. 1989. 'Storm surges in the Arabian Gulf’. Natural Hazards 1, pp. 371-385.

[5] http://www.emirates247.com/news/emirates/uae-stormweather-sub-zero-mercury-rain-2015-02-24-1.581548 (accessed March 14, 2015).

[6] Fraile-Jurado, Pablo and Ojeda-Zújar, José. 2012. 'The importance of the vertical accuracy of digital elevation models in gauging inundation by sea level rise along the Valdelagrana beach and marshes (Bay of Cádiz, SW Spain)'. Geo-Mar Lett 33, pp. 225-230.

[7] G.G. Garland. 2010. 'Rising sea level and long term sustainability of near-shore islands of the United Arab Emirates: an approach to establishing setback lines for Abu Dhabi'. Transactions on Ecology and the Environment, Vol 130, pp. 135-146.

[8] Goble, B.J. and Mackay, C.F. 2013. 'Developing risk set-back lines for coastal protection using shoreline change and climate variability factors'. Proceedings 12 th International Coastal Symposium (Plymouth, England), Journal of Coastal Research, Special Issue No. 65, pp. $2125-2130$

[9] Goudie, A. S., Parker, A. G. and Al-Farraj, A. 2000. 'Coastal Change in Ras Al Khaimah (United Arab Emirates): A Cartographic Analysis'. The Geographical Journal, Vol. 166, No. 1 (Mar., 2000), pp. 14-25.
[10] Hamdan, Fouad. April 2007. Executive Magazine.

[11] Hosseinibalam, F., Hassanzadeh, S., \& Kiasatpour. A. 2007. 'Interannual variability and seasonal contribution of thermal expansion to sea level in the Persian Gulf'. Deep Sea Research Part 1: Oceanographic Research Papers 54 (9), pp. 1474-1485.

[12] IPCC,' Synthesis Report adopted by IPCC Plenary XXVII'. 2007. (Valencia, Spain, November 27-30, pp. 34-76.

[13] IPCC UN (International Panel on Climate Change). 2013. Climate Change 2013: The Physical Science Basis. Cambridge University Press.

[14] Kellet, Jon, Balston, Jacqueline and Weston, Mark. (2014) 'Sea-Level rise and planning: retrospect and prospect'. Australian Planner. Vol. 51, No. 3, pp.203211.

[15] Mangor, K., Mocke, G., Giarusso, C., Smit, F., Bloch, R., Fuchs, J., Lumborg, U. \& Neimann, S. 2008. 'Shoreline management of the Dubai coast'. COPEDEC VII, Dubai 24-28 Feb, Paper M-15, pp 134 145 .

[16] Muthusankar, G., Lakshumanan, C., Pradeep-Kishore, V., Eswaramoorthi, S., Jonathan M. P. 2013 'Classifying inundation limits in SE coast of India: application of GIS'. Natural Hazards 65, pp. 24012409.

[17] Neelamani, S., Al-Salem, K., \& Rakha, K. 2007. 'Extreme waves in the Arabian Gulf'. Journal of Coastal Research, SI 50 (Proceedings of the $9^{\text {th }}$ International Coastal Symposium), pp. 322 - 328.

[18] Nicholls, R. J. 2002. 'Analysis of global impacts of sealevel rise: A case study of flooding'. Physics and Chemistry of the Earth, 27, pp. 1455-1466.

[19] Nicholls, R.J., 2004, 'Coastal flooding and wetland loss in the 21st century: changes under the SRES climate and socio-economic scenarios'. Global Environmental Change, 14, pp. 69-86.

[20] Pfeffer, W., T., Harper, J., T., \& O'Neel, S. 2008. 'Kinematic constraints on Glacier contributions to $21 \mathrm{st}$ century sea Level rise'. Science 5, Vol 321, no. 5894, pp. 1304-1343.

[21] Poulter, B. and Halpin, P.N. 2008. 'Raster modelling of coastal flooding from sea-level rise'. International Journal of Geographical Information Science, 22:2, pp. 167-182. 
[22] Rahmsdorf, S., Cazenave, A., Church, J., Hansen, J., Keeling, R., Larker, D. \& Somerville, R. 2007 'Recent climate observations compared to future projections'. Science 316, p709.

[23] Sanders, Brett F. 2007. 'Evaluation of on-line DEMs for flood inundation modeling'. Advances in Water Resources 30, pp. 1831-1843.

[24] Stokke, Knut Bjorn. 2014 'Adaptation to sea-level rise in spatial planning - experiences from coastal towns in Norway'. Ocean and Coastal Management. 94, pp. 6673.
[25] Sultan. S., A., R., Ahmad, F., El Ghribi, N., M., \& Al Subhi, A., M. 1995. 'An analysis of Gulf monthly mean sea level', Continental Shelf Research 15, No 11/12, pp. 1471-1482.

[26] Taylor, Bruce M., Harman, Ben P. and Inman, Matthew. 2013. 'Scaling-Up, Scaling-Down and Scaling-Out: Local planning strategies for sea-level rise in New South Wales, Australia'. Geographical Research.August 2013, 51(3), pp. 292-303.

[27] University of Texas Libraries, The University of Texas.http://www.lib.utexas.edu/maps/atlas_middle_ea st/uae_division.jpg accessed Aug. 28, 2014. 